\title{
Predictive and look-up table control methods of a three-level AC-DC converter under distorted grid voltage
}

\author{
P. FALKOWSKI*, K. KULIKOWSKI, and R. GRODZKI \\ Department of Power Electronics and Electric Drives, Bialystok University of Technology, 45D Wiejska St., 15-351 Białystok, Poland
}

\begin{abstract}
Power electronic three-level AC-DC converters connecting a utility grid with DC supplies are widely used in renewable energy sources. For such distributed systems, the quality of energy is very important. Hence, control algorithms of an AC-DC converter have to provide not only a sinusoidal shape of grid current, but also stable operation during transient states in the grid, e.g. voltage dips or voltage unbalance. This paper deals with the problem of robustness of AC-DC control methods under disturbed grid voltage. Three modern predictive control algorithms are presented and investigated under grid voltage distortions. Experimental results from a laboratory test setup illustrating properties of the described methods are shown.
\end{abstract}

Key words: three-level AC-DC converter, direct power control, finite contol set model predictive control, look-up table method.

\section{Introduction}

Three-phase active AC-DC converters are widely used to connect an AC electrical grid with a DC-link circuit. Owing to bidirectional energy flow, these converters are used in active front end to feed adjustable speed drives $[1,2]$ or in renewable energy sources (RES), e.g. wind turbines, PV panels and small hydro plants $[3,4]$. The main requirement of AC-DC converters is to provide sinusoidal shape of currents (low THD values) at low transistor switching frequency to achieve high efficiency. One of the solutions to meet those requirements is using multi-level converters [5-7]. Three-level NPC converters, due to their relatively low costs, simple structure and uncomplicated DC link voltage balancing methods [8], [9], appear to be the most commonly used [10]. Three-level converters offer great advantages as compared with typical two-level converters. For instance they ensure lower output voltage distortion (lower THD), reduce $\mathrm{du} / \mathrm{dt}$ voltage edges and decrease switching power losses, increasing efficiency [4].

The use of RES, especially hydropower, wind energy and photovoltaic technology has been constantly growing. The power produced by RES systems is supposed to reach $20 \%$ by 2020. Although the RES increase the safety of power supply, reduce the greenhouse effect, they also have some disadvantages, such as uncontrollability and limited availability depending on the weather. Without proper control, RES systems can lead to grid instability or failure. According to the present Grid Code Requirements (GCRs), such systems should properly run over short grid disturbances and ensure high power quality (low grid current distortion and unity power factor). That is why appropriate control of grid-connected converters is essential.

*e-mail: p.falkowski@pb.edu.pl

Manuscript submitted 2017-03-24, revised 2017-05-19, initially accepted for publication 2017-06-12, published in October 2017.
Principally, there are three groups of strategies used to control converters. The most popular ones are: the voltage oriented control (VOC) method with linear PI controllers and space vector modulation (SVM) or pulse width modulation (PWM) [11]; the DPC method with either linear (PI-SVM) [12] or nonlinear controllers [13]; and finally predictive control methods $[14,15]$.

Conventional linear control methods, such as VOC and DPC-SVM, are designed to control only the fundamental component of current. In order to fulfill GCRs and achieve robustness under grid voltage distortion, these linear methods need additional compensation algorithms that, in turn, increase their complexity [16]. There are many publications concerning improvements of the classical control methods in order to ensure proper converter operation under grid voltage distortions [17-19]. However, there are only few that relate to non-linear or predictive control methods of AC-DC converters under grid voltage distortion $[20,21]$.

This paper presents three modern non-linear control algorithms. The first one, direct power control three levels three areas (DPC-3L-3A) [13], is an extended version of the look-up table DPC with new optimal error plane distribution as well as with transfer of the error vector into a new coordinate system. Selection of the converter voltage vector is based on the error vector angle, which makes it possible to eliminate the inconvenience of using comparators. The second method presented here, called predictive control of current of three-level converter (PCi-3L) [22], belongs to the group of finite control set model predictive control methods (FCS-MPC). In the PCi-3L strategy the switches are controlled directly without modulation. This is performed by online minimizing of specific cost function $J$. Depending on the definition cost function, we can control many different variables, e.g. current, dc-link voltage, switching frequency, etc. Cost function is calculated for all converter voltage vectors. Minimum value of $J$ determines the optimal switching combinations. 


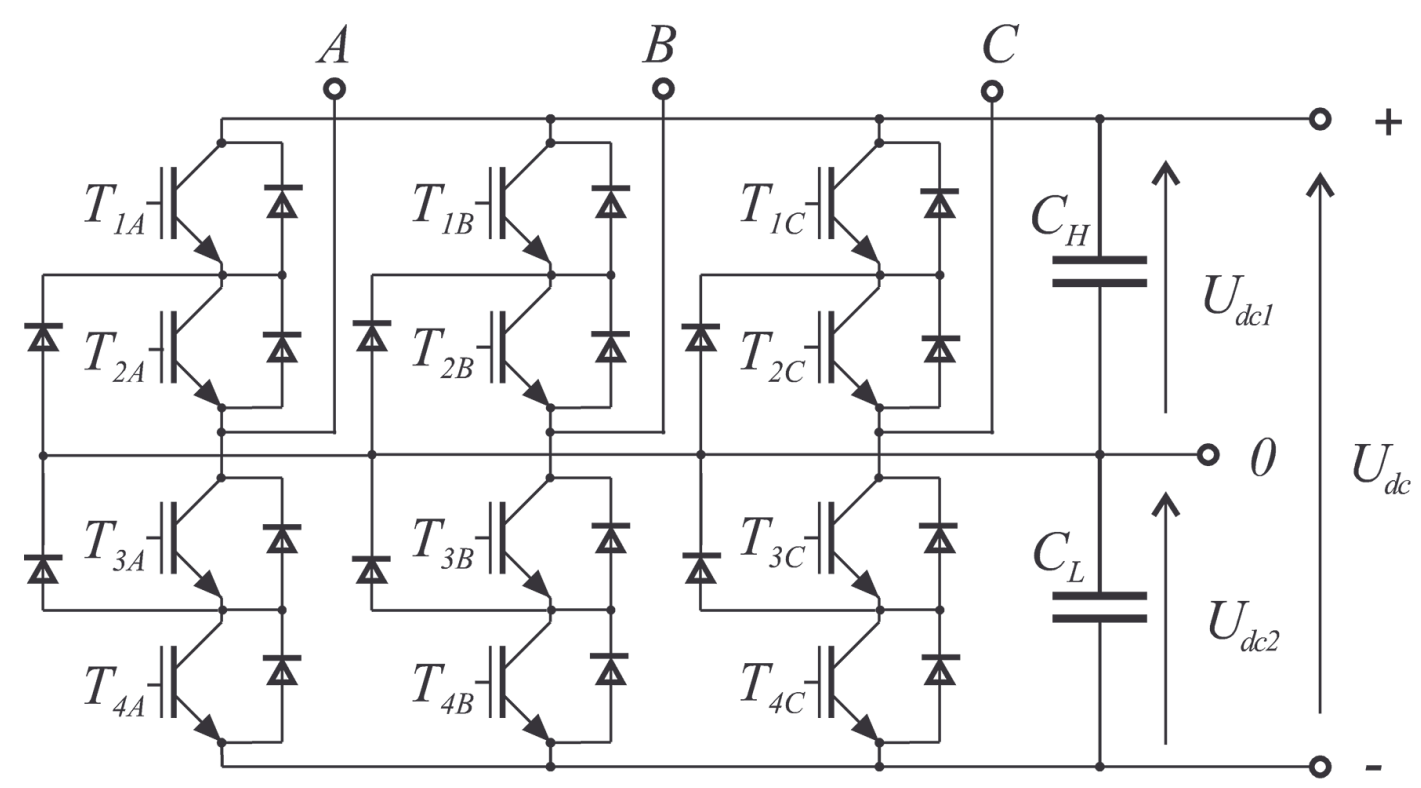

Fig. 1. Three-level NPC converter

The third method, i.e. the predictive direct power control of three-level converter with three vector modulation strategy (DPC-3V-3L), is based on the analysis of all possible locations of the current vector error in the next control step. This procedure makes it possible to choose three voltage vectors that ensure compensation of the error vector during one sampling period. Applying three-vector modulation provides constant switching frequency and excellent steady state performance.

The paper is organized as follows. In Section 2, a mathematical model of a three-level converter is described. Section 3 briefly presents the principles of operation of the above modern non-linear control methods of the ACDC converter. The results of the laboratory investigations presented in Section 4 are focused on the performance of an AC-DC converter control system under grid disturbances such as harmonic distortion, voltage unbalance and dips. The results confirm that all the proposed methods work properly under grid distortions ensuring low THD and a sinusoidal shape of the grid current in all the investigated cases.

\section{Mathematical model of three-level AC-DC converter connected to three-phase grid}

Three-level converter (Fig. 1) output voltage can be described as a complex space vector (1) in $\alpha \beta$ stationary reference frame:

$\boldsymbol{u}_{x y}[n]=\left\{\begin{array}{l}\frac{2}{3} U_{d c} \cdot e^{j(n-21) \frac{\pi}{3}}, \text { for } \mathrm{n}=\{21,22 \ldots, 26\} \\ \frac{\sqrt{3}}{3} U_{d c} \cdot e^{j\left((n-15) \frac{\pi}{3}+\frac{\pi}{6}\right)}, \text { for } \mathrm{n}=\{15,16 \ldots, 20\} \\ \frac{1}{3} U_{d c} \cdot e^{j(n-3) \frac{\pi}{3}}, \text { for } \mathrm{n}=\{3,4 \ldots, 14\} \\ " 0 ", \text { for } \mathrm{n}=\{0,1,2\}\end{array}\right.$ where: $U_{d c}-$ DC link voltage, "0" - zero vector, $n$ - vector number.

Complex space vector equation (2) in the rotating $x y$ reference frame gives a clear description of the configuration of the three-level AC-DC converter (Fig. 2):

$$
\boldsymbol{e}_{x y}=L \frac{d}{d t} \boldsymbol{i}_{x y}+j \omega_{g} L \boldsymbol{i}_{x y}+\boldsymbol{u}_{x y}
$$

where: $\boldsymbol{i}_{x y}$ - grid current vector in $x y$ rotating reference frame, $L$ - grid reactor inductance, $\boldsymbol{e}_{x y}$ - grid voltage vector, $\boldsymbol{u}_{x y}$ - threelevel converter voltage vector, $\omega_{g}$ - grid voltage pulsation.

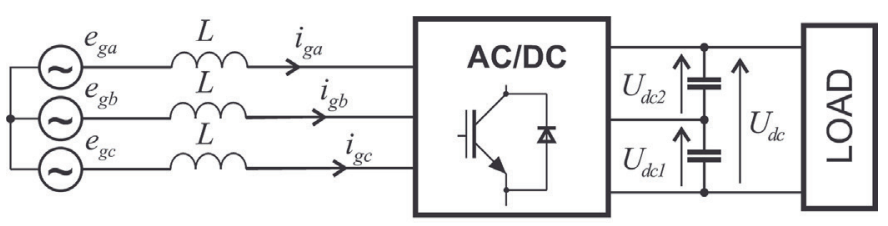

Fig. 2. Schematic diagram of AC-DC converter

From (3) it is possible to obtain both the vector proportional to the derivative vectors of the grid current and the derivative of the grid current vector [8]:

$$
\begin{aligned}
L \frac{d}{d t} \boldsymbol{i}_{x y} & =L \boldsymbol{d}_{i x x x}=\boldsymbol{d}_{u x x x}= \\
& =\boldsymbol{e}_{x y}-j \omega_{g} L \boldsymbol{i}_{x y}-\boldsymbol{u}_{x y}=\boldsymbol{u}^{*}-\boldsymbol{u}_{x y}
\end{aligned}
$$

where the " $\mathrm{xxx}$ " index is the number identifying the converter voltage vector, for example, 110, 010, 202 etc. 
a)

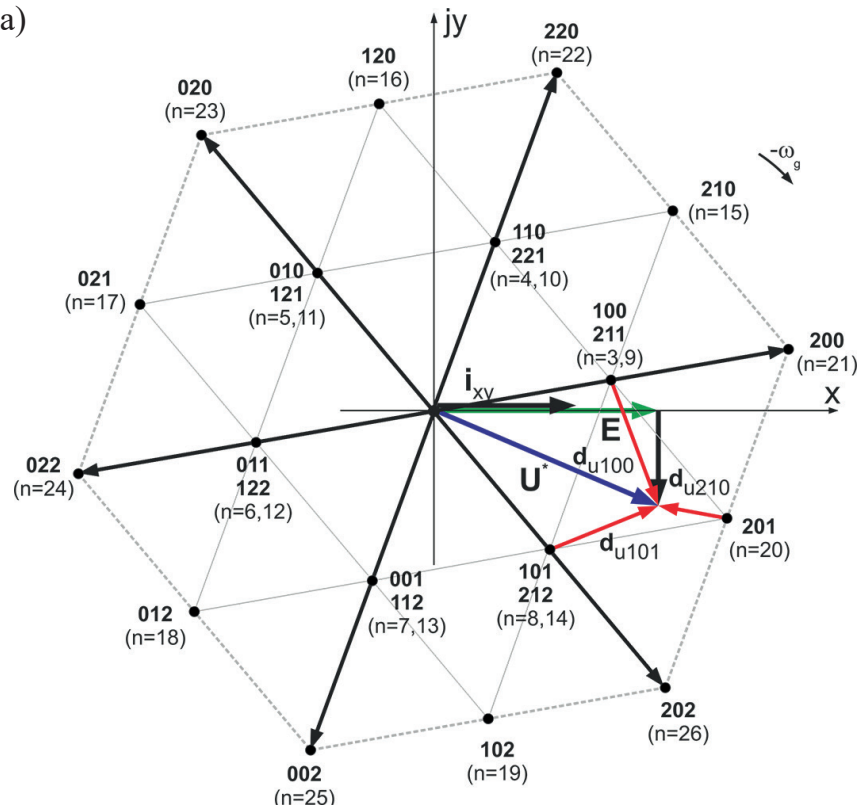

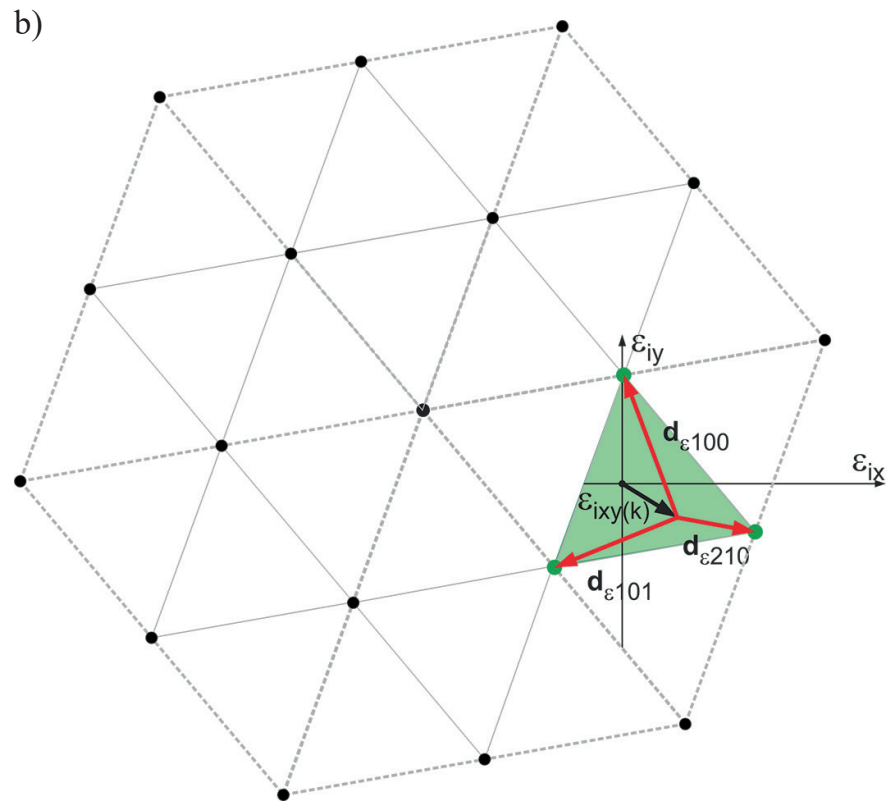

b)

Fig. 3. Graphic representation of the converter voltage vectors in the $x y$ reference frame for three-level converter (a); the influence of error vectors $\boldsymbol{d}_{\varepsilon x x x}$ on the grid current error vector and the possibilities of error vector minimization (b)

Figure 3 shows a graphical form of equation (3). Current derivative vectors $\boldsymbol{d}_{i x x x}$ describe both the direction and rate of change of the current vector caused by switching on an appropriate voltage vector of the converter.

\section{Control methods}

3.1. DPC-3V-3L method. The predictive control DPC3V-3L control method presented in this paper is based on the analysis of the influence of the selected converter voltage vector on the complex grid current error vector $\boldsymbol{\varepsilon}_{i x y}$. The $\boldsymbol{\varepsilon}_{i x y}$ vector, expressed in the rotating $x y$ reference frame, is defined as follows:

$$
\boldsymbol{\varepsilon}_{i x y}=\varepsilon_{i x}+j \varepsilon_{i y}
$$

Error vector changes are determined by the vector opposite to the grid current derivative vector $\boldsymbol{d}_{\text {ixxx }}$. Taking the above into account, we can calculate the error vector in the next sampling period as follows $[8,15]$ :

$$
\boldsymbol{\varepsilon}_{i x y(k+1)}=\boldsymbol{\varepsilon}_{i x y(k)}+\boldsymbol{d}_{\varepsilon x x x},
$$

where: $\boldsymbol{d}_{\varepsilon x x x}=-T_{s} \cdot \boldsymbol{d}_{i x x x}[15]$.

In nonlinear DPC and most of FCS-MPC methods, only one voltage vector of the converter is used during one sampling period. As a result, the possibilities of minimizing the current error are limited. This situation is shown in Fig. 3b. The error vector after $T_{s}$ sampling time can be moved to one of the points defined by appropriate vectors $\boldsymbol{d}_{\varepsilon x x x}$ (Fig. 3b). But if we use three appropriate voltage vectors (similar to the PWMbased methods) during a single sample period, the predicted error vector $\boldsymbol{\varepsilon}_{i x y(k+1)}$ can be placed at any point lying inside an equilateral triangle defined direction vectors $\boldsymbol{d}_{\text {Exxx }}$. DPC-3V-3L determines the equilateral triangle in which the origin of the error reference frame lies, chooses three optimal voltage vectors and, finally, calculates their application times in order to compensate grid current error vector. The idea of the proposed DPC-3V-3L method is shown in Fig. 4.

The predicted error vector at the end of sampling period is expressed as follows:

$$
\begin{aligned}
\boldsymbol{\varepsilon}_{i x y(k+1)} & =\boldsymbol{\varepsilon}_{i x y(k)}+a_{110} \cdot \boldsymbol{d}_{\varepsilon 110}+ \\
& +a_{010} \cdot \boldsymbol{d}_{\varepsilon 010}+a 0{ }^{\prime \prime} \\
& \cdot \boldsymbol{d}_{\varepsilon^{\prime \prime} 0 "}=0
\end{aligned}
$$

where $a_{\mathrm{xxx}}$ are the relative voltage vector application times (in the range from 0 to 1 ).

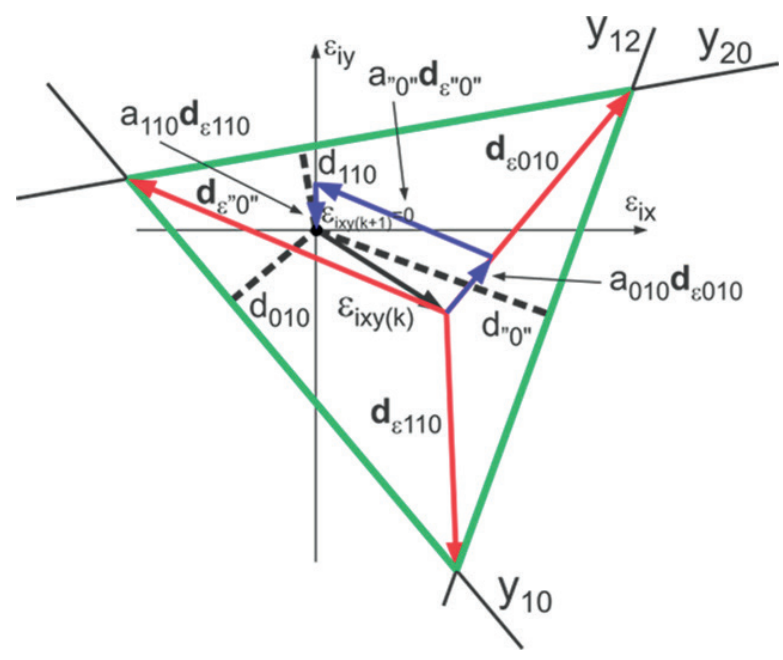

Fig. 4. The idea of predictive DPC-3V-3L method in steady state 
Figure 4 shows that if the voltage vector application times are properly calculated, the predicted error vector is equal to zero, which means that the $x$ and $y$ axis current errors have been exactly compensated. The main goal of this predictive control is to calculate optimal vector application times:

$$
t_{110}=a_{110} \cdot T_{s}, \quad t_{010}=a_{010} \cdot T_{s}, \quad t_{1 " 0 "}=a_{1 " 0 "} \cdot T_{s},
$$

where $t{ }^{\prime \prime}, t_{010}$ and $t_{110}$ - active and zero voltage vectors application time, respectively.

The exact values of relative times $a_{x x x}$ are determined by the geometric relationship occurring in the equilateral triangle shown in Fig. 4. It was theoretically proved that equation (6) is satisfied if $a_{110}, a_{010}$ and $a{ }^{\prime \prime}$ coefficients are given as follows [15]:

$$
a_{110}=\frac{d_{110}}{h}, a_{010}=\frac{d_{010}}{h}, a_{" 0 "}=\frac{d^{\prime \prime} 0^{\prime}}{h},
$$

where $h$ is the height of the equilateral triangle and is expressed as:

$$
h=\frac{\sqrt{3} U_{D C}}{6 L},
$$

while $d_{\mathrm{xxx}}$ are the distances from the origin of the reference frame to each of the three lines containing a side of the triangle.

In transient states the control algorithm can choose different voltage vectors, but the idea of control is the same. If the origin of the reference frame from Fig. 4 lies outside of the hexagon (from Fig. 3b), the control algorithm will select one optimal voltage vector and switch it on for the whole sampling period.

3.2. DPC-3L-3A method. The behavior of the DPC3L3A method depends on the converter state (Fig. 5a). In steady states the selection of the converter voltage vector is based on the angle of error vector in specific reference frame (10) [13].
Table 1

Voltage vector selection table for DPC-3L-3A method

\begin{tabular}{|c|c|c|c|c|c|c|c|}
\hline \multirow{4}{*}{$\varphi_{\varepsilon_{g}^{*}}$} & \multirow{2}{*}{ triangle } & \multicolumn{7}{|c|}{ Sector $N$} \\
\cline { 2 - 8 } & $N=1$ & $N=2$ & $N=3$ & $N=4$ & $N=5$ & $N=6$ \\
\hline \multirow{5}{*}{$\left(-\pi ; \frac{-\pi}{3}\right)$} & tr. 0 & 010 & 011 & 001 & 101 & 100 & 110 \\
\cline { 2 - 8 } & tr. I & 120 & 021 & 012 & 102 & 201 & 210 \\
\cline { 2 - 8 } & tr. II & 010 & 011 & 001 & 101 & 100 & 110 \\
\cline { 2 - 8 } & tr. III & 020 & 022 & 002 & 202 & 200 & 220 \\
\hline \multirow{5}{*}{$\left(-\frac{\pi}{3} ; \frac{\pi}{3}\right)$} & tr. 0 & 000 & 000 & 000 & 000 & 000 & 000 \\
\cline { 2 - 8 } & tr. I & 110 & 010 & 011 & 001 & 101 & 100 \\
\cline { 2 - 8 } & tr. II & 120 & 021 & 012 & 102 & 201 & 210 \\
\cline { 2 - 7 } & tr. III & 010 & 011 & 001 & 101 & 100 & 110 \\
\hline \multirow{3}{*}{$\left(\frac{\pi}{3} ; \pi\right)$} & tr. 0 & 110 & 010 & 011 & 001 & 101 & 100 \\
\cline { 2 - 7 } & tr. I & 220 & 020 & 022 & 002 & 202 & 200 \\
\cline { 2 - 7 } & tr. II & 110 & 010 & 011 & 001 & 101 & 100 \\
\cline { 2 - 7 } & tr. III & 120 & 021 & 012 & 102 & 201 & 210 \\
\hline
\end{tabular}

The choice is optimized by selecting converter voltage vector $\boldsymbol{u}_{x x x}$ that decreases the absolute value of the error vector by the use of the shortest current derivative vectors. That allows us to achieve both low switching frequency and high accuracy of control. In the steady state selection of a converter, voltage vector is determined by $N$ sector number, triangle number (Fig. 5b), as well as error vector angle $\varphi_{\varepsilon_{g}^{\prime \prime}}(10)$ according to the vector selection table (Table 1).

$$
\varphi_{\varepsilon_{g}^{\prime \prime}}= \begin{cases}\varphi\left(\varepsilon_{g}^{\prime \prime}\right), & \text { if } \boldsymbol{u}^{*} \text { is located in } \\ \varphi\left(-\operatorname{Re}\left(\varepsilon_{g}^{\prime \prime}\right)+j \operatorname{Im}\left(\varepsilon_{g}^{\prime \prime}\right)\right), & \text { if. } 0, \text { I, III } \\ \boldsymbol{u}^{*} \text { is located in tr. II }\end{cases}
$$

where $\varphi_{\varepsilon_{g}^{\prime \prime}}$ angle of $\varepsilon_{g}^{\prime \prime}$ vector (11). a)

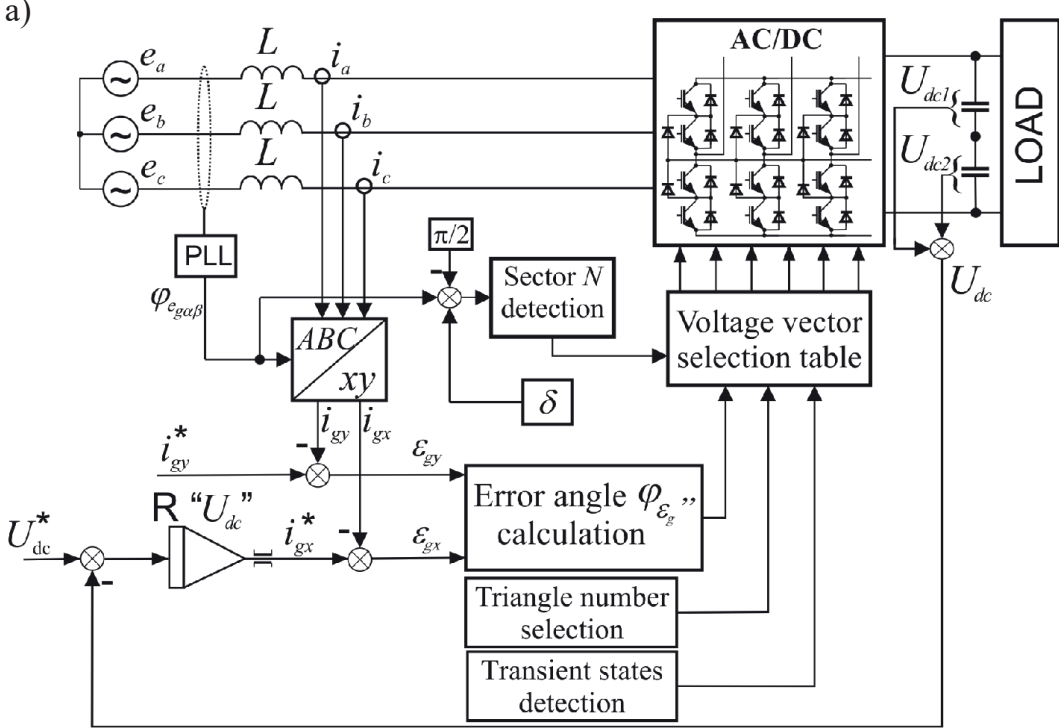

b)

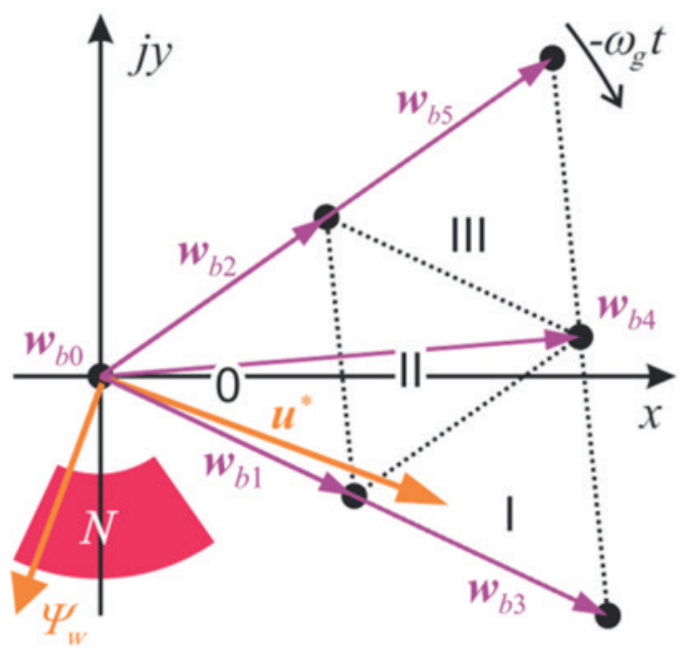

Fig. 5. Schematic diagram of the DPC-3L-3A method (a), triangle numbers assignation and graphical interpretation of the $\boldsymbol{w}_{b x}$ vectors (b) 


$$
\varepsilon_{g}^{\prime \prime}=\left(\varepsilon_{g}+\frac{T_{s}}{L}\left(s_{g}-\boldsymbol{u}^{*}\right)\right) \cdot e^{-j \varphi_{w_{b 4}}}
$$

where: $\boldsymbol{s}_{g}$ - vector of triangle center (12), $\varphi_{\boldsymbol{w}_{b 4}}-$ angle of the $\boldsymbol{w}_{b 4}$ vector (Fig. 5b).

$s_{g}= \begin{cases}1 / 3\left(\boldsymbol{w}_{b 0}+\boldsymbol{w}_{b 1}+\boldsymbol{w}_{b 2}\right), & \text { if } \boldsymbol{u}^{*} \text { is located in tr. } 0 \\ 1 / 3\left(\boldsymbol{w}_{b 1}+\boldsymbol{w}_{b 3}+\boldsymbol{w}_{b 4}\right), & \text { if } \boldsymbol{u}^{*} \text { is located in tr. I } \\ 1 / 3\left(\boldsymbol{w}_{b 1}+\boldsymbol{w}_{b 2}+\boldsymbol{w}_{b 4}\right), & \text { if } \boldsymbol{u}^{*} \text { is located in tr. II } \\ 1 / 3\left(\boldsymbol{w}_{b 2}+\boldsymbol{w}_{b 4}+\boldsymbol{w}_{b 5}\right), & \text { if } \boldsymbol{u}^{*} \text { is located in tr. III }\end{cases}$

where: tr. 0, I, II, III - triangles constructed by $\boldsymbol{w}_{b x}$ vectors in actual $N$ sector (Fig. 5 b).

In transient states the selected voltage vectors decrease both components of the error vector by the use of the converter voltage vector corresponding to the longest current vector derivatives in $x$ axis [8]. That enables fast response to dynamic changes of currents. The transient state in the DPC-3L-3A is chosen in the case when the component $x$ of the $\varepsilon_{i x y}$ vector exceeds the $\varepsilon_{x d y n}$ value (13) that corresponds to the maximum changes of error vector component in the steady state during one sampling period. Due to the fact that the current vector in the DPC3L-3A method is formed by the converter voltage vectors that form an equilateral triangle, $\varepsilon_{x d y n}$ value is defined as a length of the triangle side with the ratio of $T_{S} / L(13)$.

$$
\varepsilon_{x d y n}=\frac{1}{3} U_{d c} \frac{T_{s}}{L}
$$

3.3. PCi-3L method is variation of FCS-MPC method [22]. In this strategy the switches are controlled directly without modulation. This is performed by online minimizing of the specific cost function $J$. It means that at each step $k$, the impact of all converter voltage vectors $\boldsymbol{u}_{x y}$ on converter current vector $\boldsymbol{i}_{x y}$ (proportional to the active and reactive power) is examined.

When equation (3) is applied (as shown in Fig. 3a), the predicted current vector $\boldsymbol{i}_{x y}(k+1)$ can be determined by:

$$
\begin{gathered}
\Delta \boldsymbol{i}_{x y}(k+1)=\frac{1}{L}\left(\boldsymbol{u}_{x y}^{*}(k+1)-\boldsymbol{u}_{x y}(k+1)\right) T_{s} \\
\boldsymbol{i}_{x y}(k+1)=\boldsymbol{i}_{x y}(k)+\Delta \boldsymbol{i}_{x y}(k+1) .
\end{gathered}
$$

Predicted current error in next sample time $(k+1) T_{s}$ is calculated using the following equation:

$$
\boldsymbol{\varepsilon}_{i x y}(k+1)=\boldsymbol{i}_{x y}^{*}(k+1)-\boldsymbol{i}_{x y}(k+1) .
$$

The final step of the algorithm is calculating cost function $J(17)$ and choose the best converter voltage vector $\boldsymbol{u}_{x y}(k+1)$ :

$$
J=\varepsilon_{i x}(k+1)^{2}+\varepsilon_{i y}(k+1)^{2}+w_{f s w} n_{s w}
$$

where: $\varepsilon_{i x}, \varepsilon_{i x}-x$ and $y$ axis components of error vector (16), $w_{f s w}$ - weighting factor, $n_{s w}$ - predicted number of switching. The $n_{s w}$ component included in cost function $J$ is responsible for average switching frequency $f_{s w}$ reduction. The predicted number of switching is obtained as follows:

$$
\begin{aligned}
n_{s w} & =\left|S_{a}(k+1)-S_{a}(k)\right|+\left|S_{b}(k+1)-S_{b}(k)\right|+ \\
& +\left|S_{c}(k+1)-S_{c}(k)\right|
\end{aligned}
$$

where: $S_{x}(k+1)$ is the predicted switching state for next sampling period $(k+1) T_{s}$. $S_{x}(k)$ is the currently used switching state. The control strategy was tested using weight factor $w_{f s w}=0.2$, adjusted based on empirical procedure, to set average switching frequency about $f_{s w}=5 \mathrm{kHz}$.

In the proposed control methods PCi-3L (Fig. 6) to avoid additional weighting factors in the cost functions $J$, a separate algorithm is used to balance voltages of DC link capacitors [8].

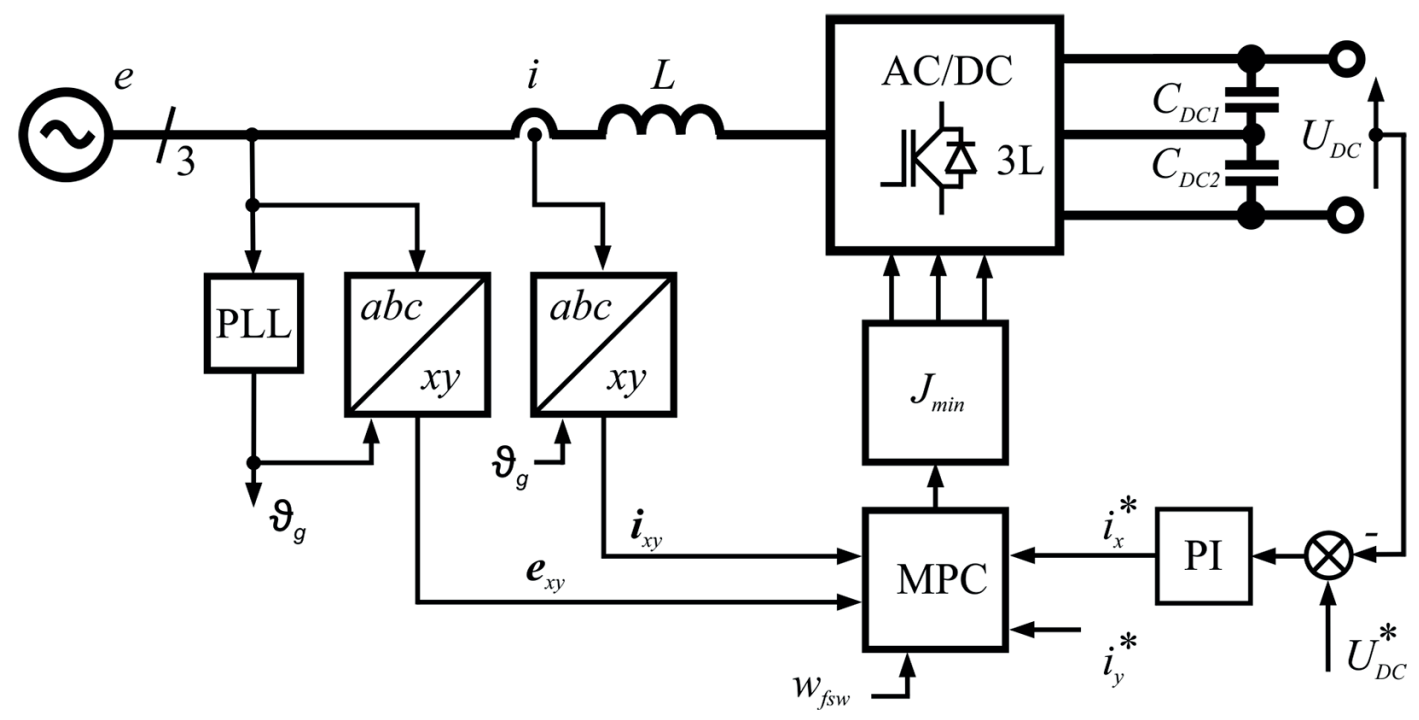

Fig. 6. Control scheme of PCi-3L method 
3.4. VOC method. VOC method, which is the most popular control algorithm of an AC-DC converter, uses closed-loop current control in rotating $x y$ reference frame $[19,23]$. The power flow is controlled indirectly by $i_{x}$ and $i_{y}$ grid current components using linear PI controllers (tuned according to [24]) and PWM technique that ensures constant switching frequency. To improve current tracking in a transient state, a decoupling network should be applied (Fig. 7).

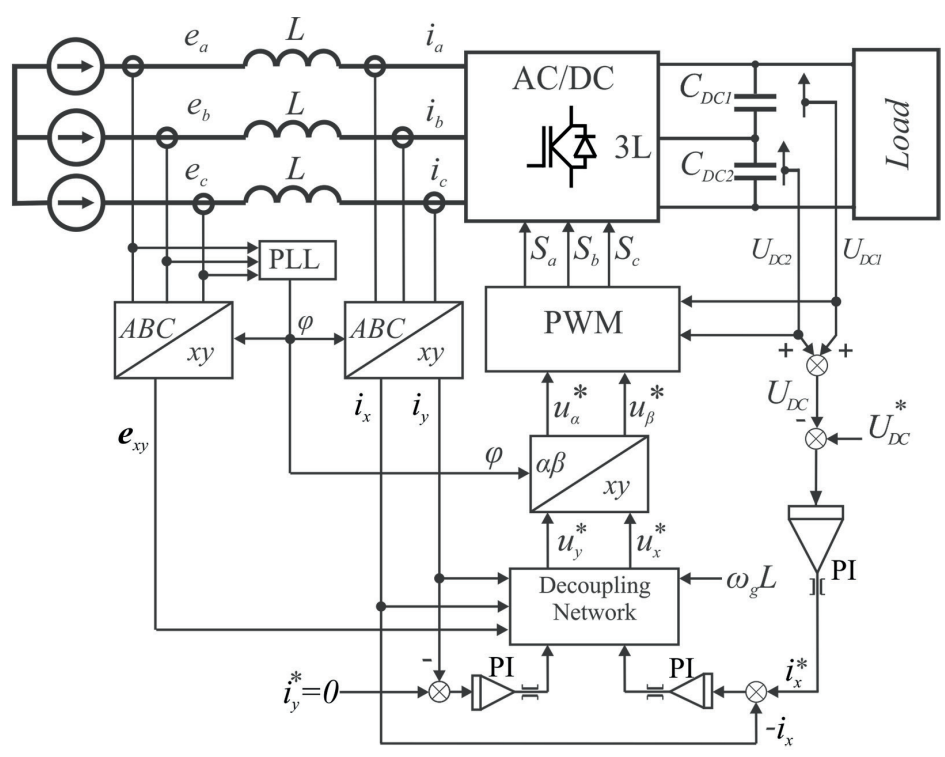

Fig. 7. Schematic diagram of VOC method

\section{Comparison of the methods}

The experimental setup consists of a three-level AC-DC converter, grid L filter with inductances amounted to $7 \mathrm{mH}$, a control unit based on SHARC ADSP-21369 microprocessor and Spartan XC3S400 FPGA. In order to simulate various grid con-

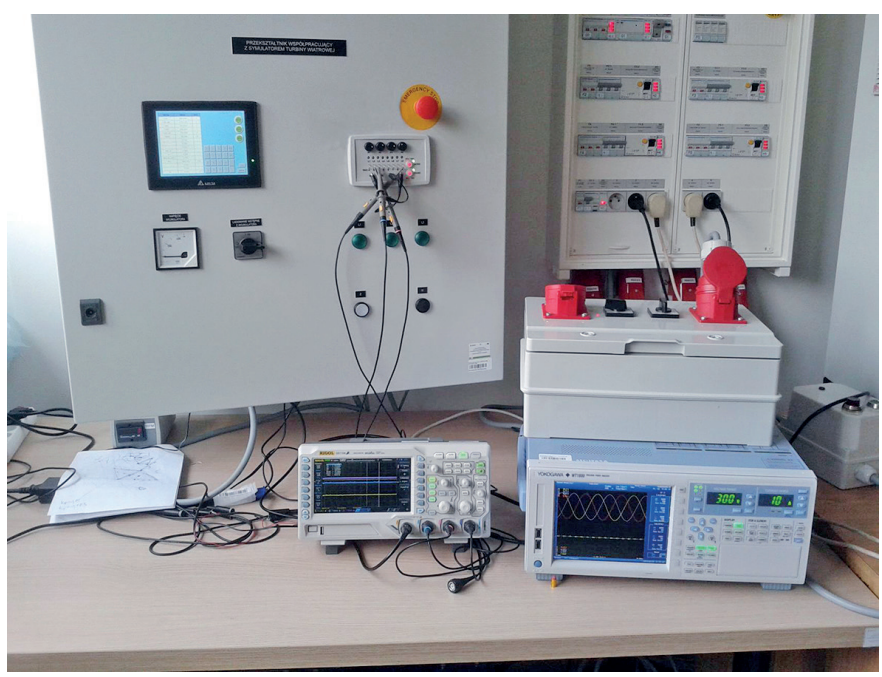

Fig. 8. Experimental setup of three-level AC-DC converter ditions the converter was supplied by the California Instruments MX30-3Pi. The measurements were made by the Yokogawa WT1800 power analyzer. The $5 \mathrm{~kW}$ resistant load was connected to DC link capacitors. In order to enable energy flow to grid in the inverter mode, the batteries by DC-DC converter were connected to DC link capacitors. The DPC-3L-3A and $\mathrm{PCi}-3 \mathrm{~L}$ methods operated with the sampling time amounted to $T_{s}=25 \mu \mathrm{s}$, whereas the DPC-3V-3L and VOC methods were tested with $T_{s}=200 \mu \mathrm{s}$. Different sampling times were used in order to achieve similar switching frequencies for all tested methods.

In steady states the experiments were performed under four conditions, i.e. a sinusoidal symmetrical supply with the RMS value of phase to phase voltages amounted to $400 \mathrm{~V}$; non-sinusoidal symmetrical supply; sinusoidal unbalanced supply; and finally for non-sinusoidal unbalanced supply. The non-sinusoidal supply was carried out by adding the 5-th and 7-th harmonics with amplitude amounted to $5 \%$ of 1 -st harmonic and 11-harmonic with amplitude amounted to $3 \%$ of 1 -st harmonic to phase voltages $(\mathrm{THD}=8.2 \%$ ). The unbalanced supply was carried out by reducing the voltage in one phase by $30 \%$.

According to Table 2, in steady states the PCi-3L method shows lowest grid current THD values for all grid conditions (4.6\% at sinusoidal balanced voltage). For the DPC-3L-3A and DPC-3V-3L methods current THDs were $4.8 \%$ and $4.85 \%$, respectively. The highest THD was for the VOC method (5.39\%). Lower THD values for the unbalanced supply are caused by the higher values of phase current which are required to maintain a constant average value of power.

Table 2

Comparison of the methods in steady states

\begin{tabular}{|c|c|c|c|c|}
\hline \multirow[b]{2}{*}{ Method } & \multicolumn{4}{|c|}{ Grid condition } \\
\hline & 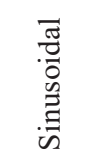 & $\begin{array}{c}\text { Higher } \\
\text { harmonics } \\
(\mathrm{THD}=8.2 \%)\end{array}$ & 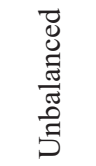 & $\begin{array}{l}\text { Unbalanced } \\
\text { and higher } \\
\text { harmonics } \\
(\mathrm{THD}=8.2 \%)\end{array}$ \\
\hline \multicolumn{5}{|c|}{ Grid current THD } \\
\hline DPC-3L-3A & $4.80 \%$ & $4.84 \%$ & $4.32 \%$ & $4.31 \%$ \\
\hline PCi-3L & $4.60 \%$ & $4.63 \%$ & $4.17 \%$ & $4.14 \%$ \\
\hline DPC-3V-3L & $4.85 \%$ & $5.64 \%$ & $4.56 \%$ & $4.74 \%$ \\
\hline VOC & $5.39 \%$ & $6.62 \%$ & $5.48 \%$ & $6.69 \%$ \\
\hline \multicolumn{5}{|c|}{$I_{p h R M S}$} \\
\hline DPC-3L-3A & 7.28 & 7.37 & 8.17 & 8.16 \\
\hline PCi-3L & 7.28 & 7.41 & 8.20 & 8.21 \\
\hline DPC-3V-3L & 7.21 & 7.41 & 8.26 & 8.07 \\
\hline VOC & 7.32 & 7.47 & 8.12 & 8.05 \\
\hline
\end{tabular}

The proposed methods are stable under unbalanced and distorted grid voltages. Only in the DPC-3V-3L method negative impact of the grid voltage higher harmonics can be seen. For 
both DPC-3L-3A and PCi-3L methods the differences between sinusoidal and non-sinusoidal supply are neglected. All three

a)

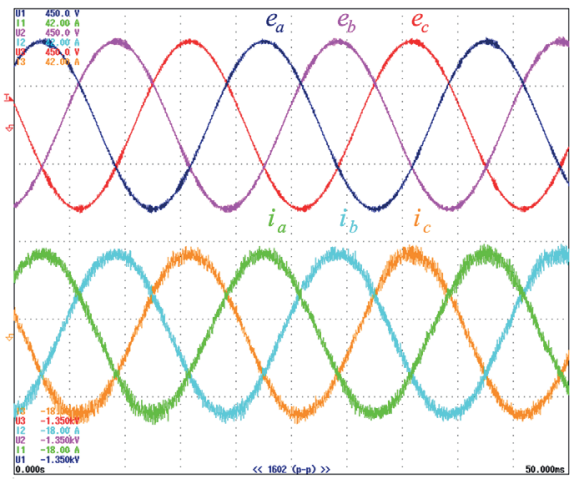

b)

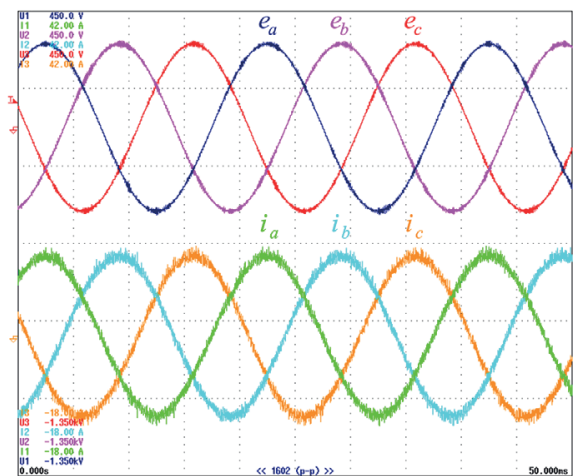

methods have shown significantly better results than the VOC method under all tested grid conditions (Table 2, Figs 9-12). c)

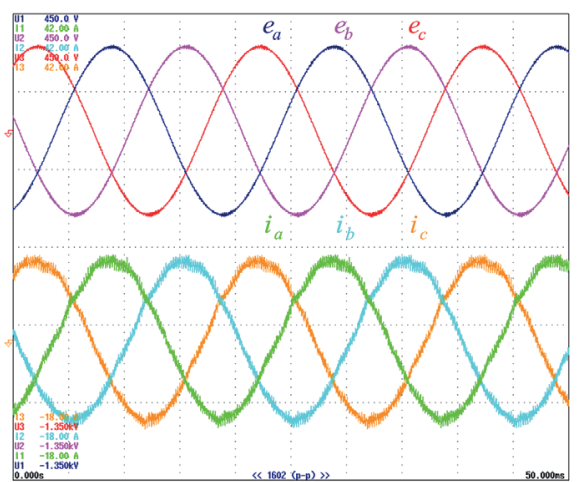

d)

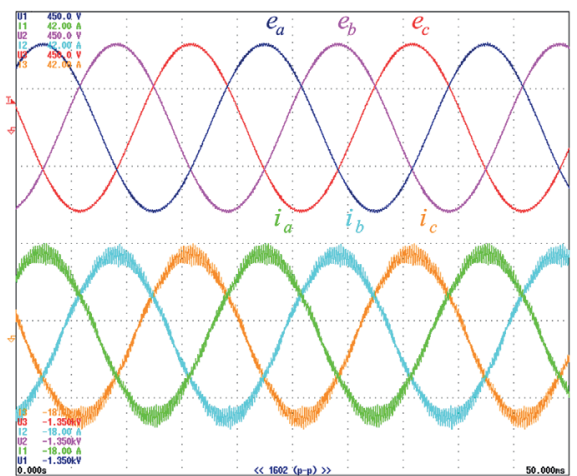

Fig. 9. Time courses of phase voltages $(300 \mathrm{~V} / \mathrm{div})$ and currents $(10 \mathrm{~A} / \mathrm{div})$ for symmetrical and sinusoidal supply for DPC-3L-3A (a), PCi-3L (b), DPC-3V-3L (c) and VOC (d) methods

a)

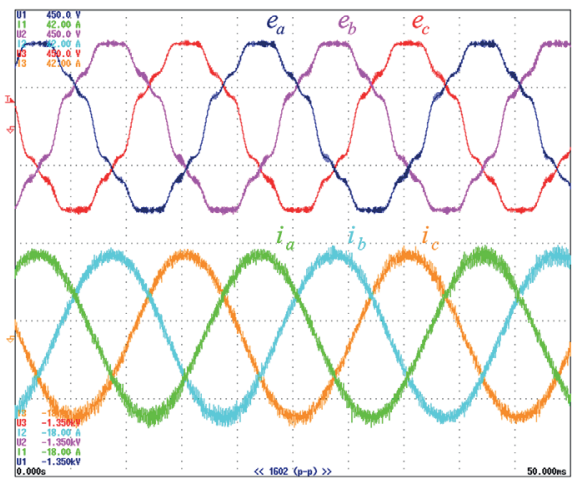

b)

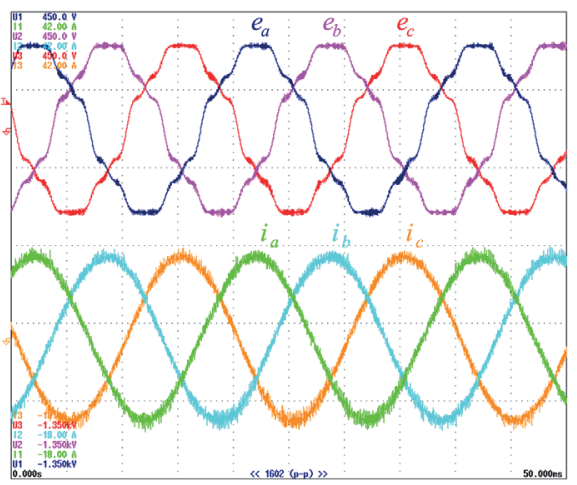

c)

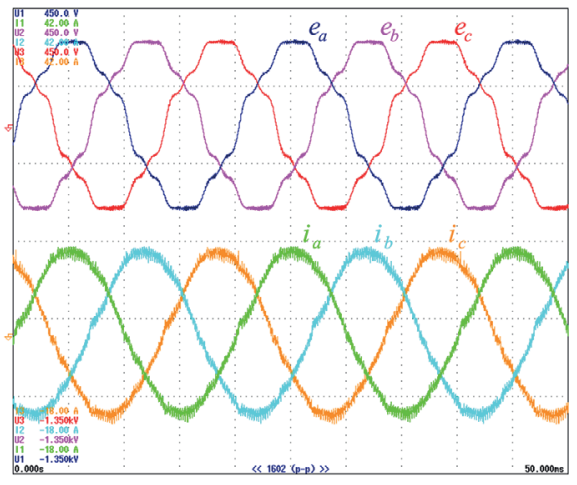

d)

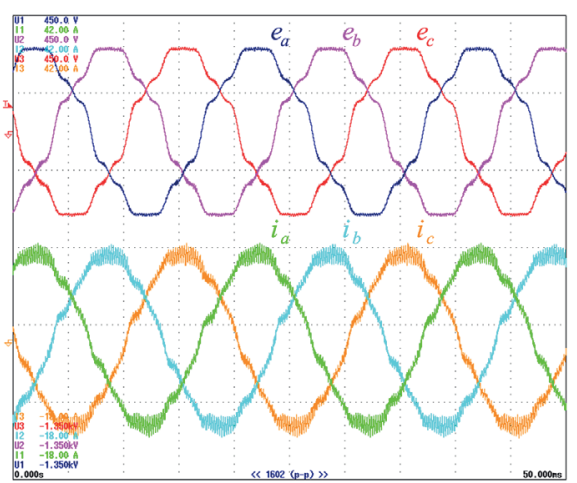

Fig. 10. Time courses of phase voltages $(300 \mathrm{~V} / \mathrm{div})$ and currents $(10 \mathrm{~A} / \mathrm{div})$ for non-sinusoidal supply for DPC-3L-3A (a), PCi-3L (b), DPC-3V-3L (c) and VOC (d) methods 
In transient states the tests verified the properties of the investigated methods under single phase voltage dips reaching $50 \%$ for sinusoidal supply (Fig. 13). A robustness test of all con- a)

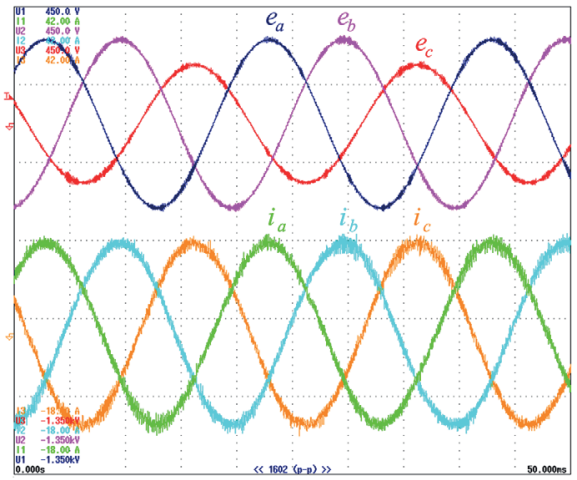

b)

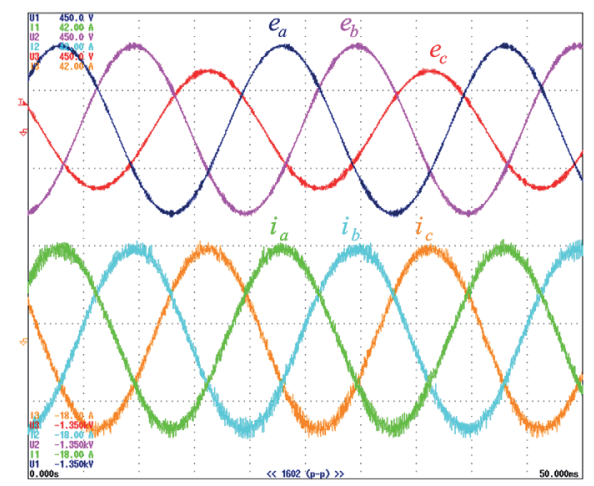

trol methods was also performed at single phase $60 \%$ voltage back to the grid (Fig. 14). As seen in Figs 13 and 14, all of the dips and non-sinusoidal supply voltage during sending energy

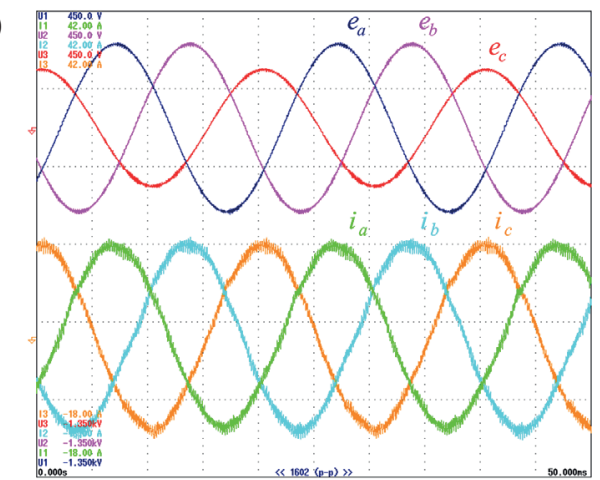

d)

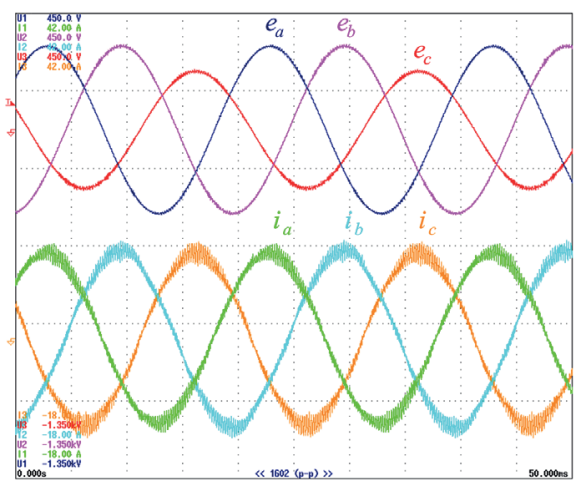

Fig. 11. Time courses of phase voltages (300 V/div) and currents (10 A/div) for $30 \%$ voltage unbalanced supply for DPC-3L-3A (a), PCi3L (b), DPC-3V-3L (c) and VOC (d) methods

a)

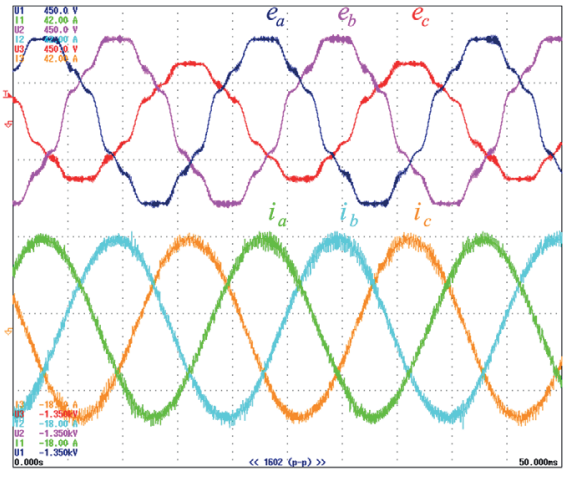

b)

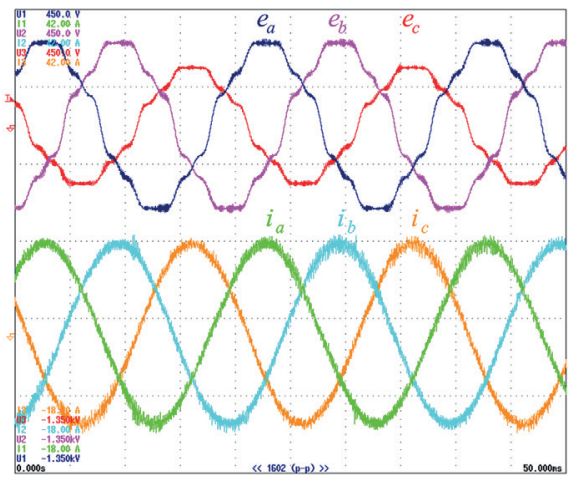

c)

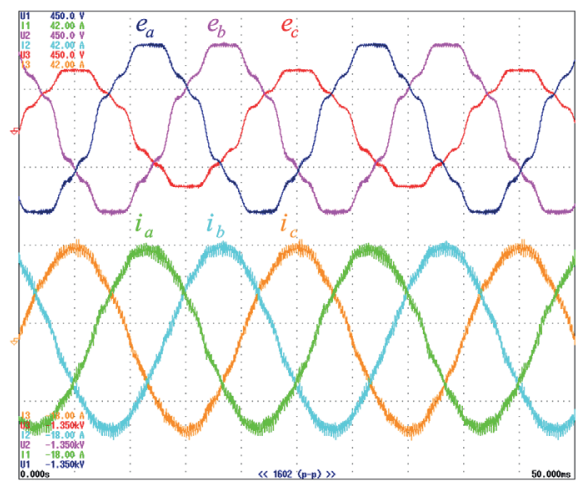

d)

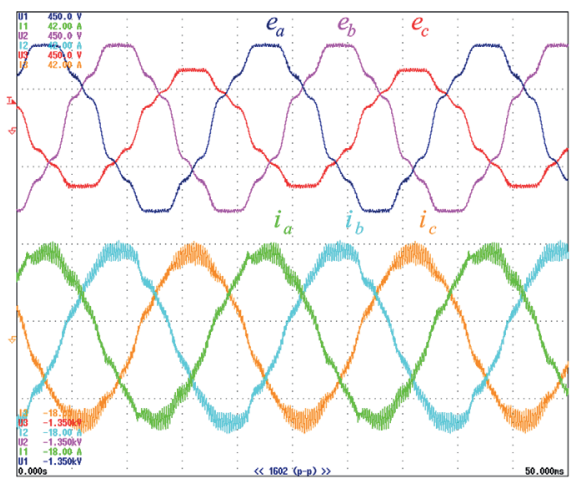

Fig. 12. Time courses of phase voltages $(300 \mathrm{~V} / \mathrm{div})$ and currents $(10 \mathrm{~A} / \mathrm{div})$ for $30 \%$ voltage unbalanced and non-sinusoidal supply for DPC-3L-3A (a), PCi-3L (b), DPC-3V-3L (c) and VOC (d) methods 
proposed methods operate in a stable way in both conditions. Only in the case of the DPC-3V-3L, due to a longer sampling period, slightly more distorted currents during voltage dips can

a)

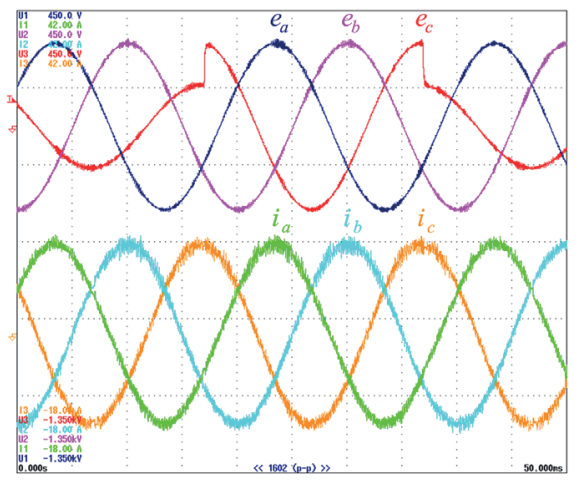

b)

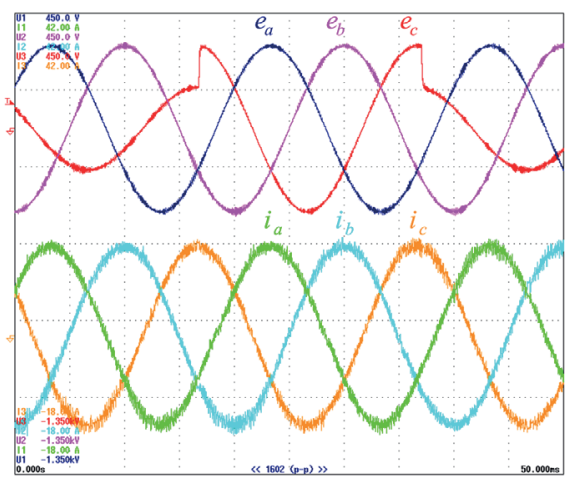

be observed. Figs 11 and 12 confirm high robustness of the three methods under grid voltage disturbances. As can be seen, the VOC method is less robust under grid voltage disturbances.

c)

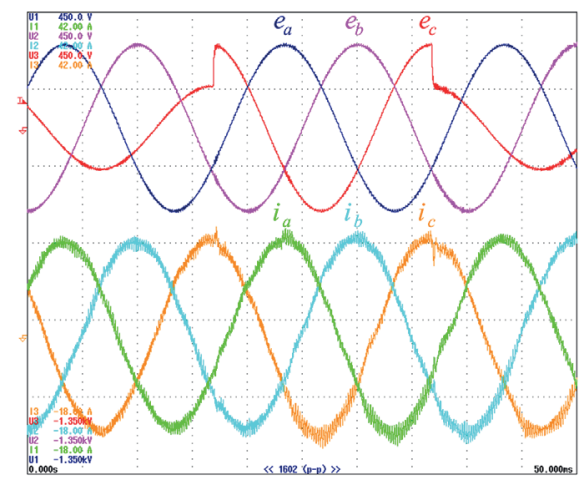

d)

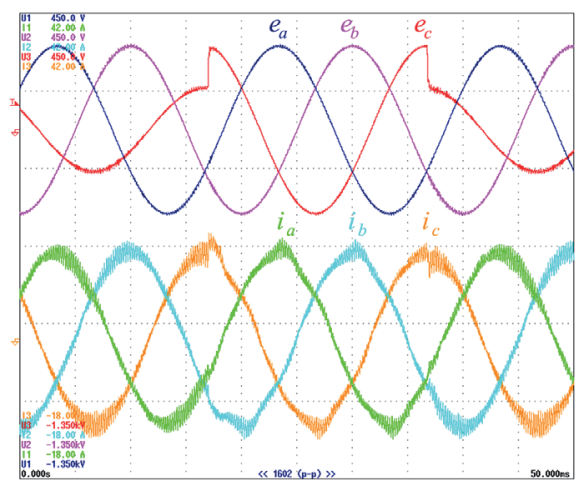

Fig. 13. Time courses of phase voltages $(300 \mathrm{~V} / \mathrm{div})$ and currents $(10 \mathrm{~A} / \mathrm{div})$ for $50 \%$ voltage dip and sinusoidal supply for DPC-3L-3A (a), PCi-3L (b), DPC-3V-3L (c) and VOC (d) methods

a)

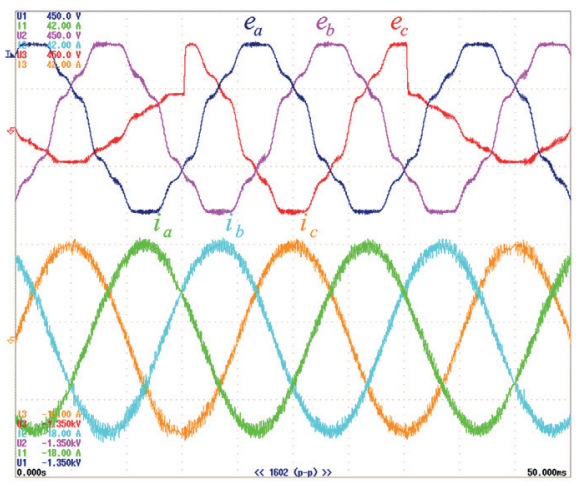

b)

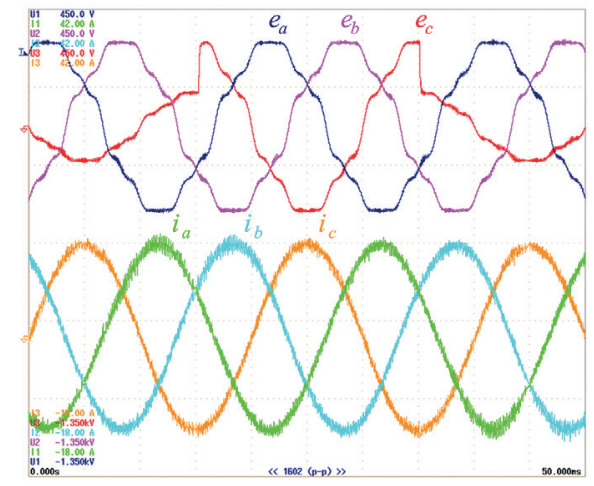

c)

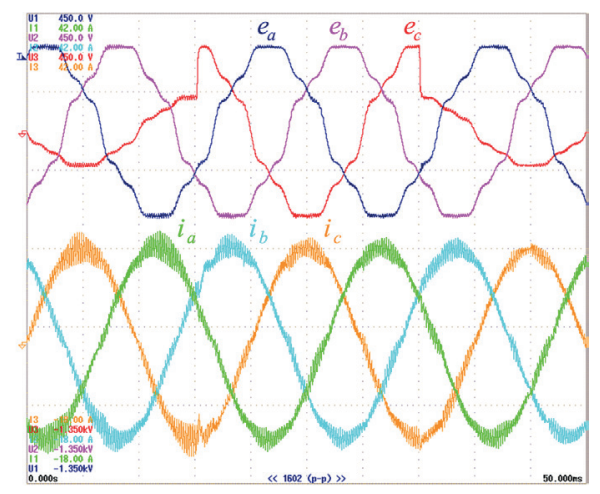

d)

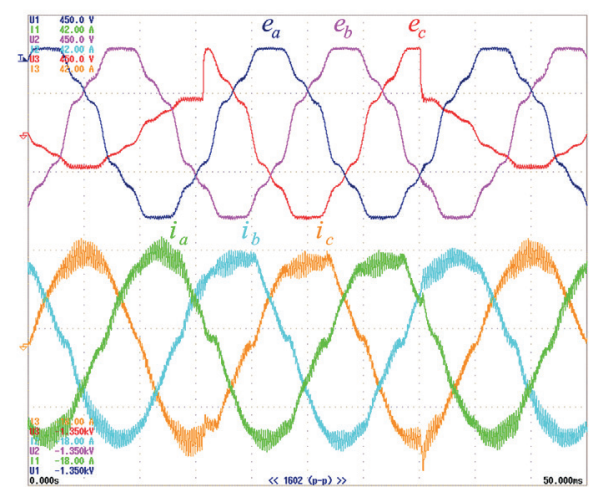

Fig. 14. Time courses of phase voltages and currents for $60 \%$ voltage dip and non-sinusoidal supply (inverter mode) for DPC-3L-3A (a), PCi-3L (b), DPC-3V-3L (c) and VOC (d) methods 
Unlike the VOC method, the proposed methods are characterized by low content of higher harmonics in currents.

\section{Conclusions}

All the investigated methods are characterized by high robustness under grid voltage distortions and are able to operate under varied grid conditions. The test results have shown that the methods operate with lower grid current THD value as compared with the VOC method. The methods provide closely a sinusoidal current shape even under unbalanced and non-sinusoidal grid voltages.

Due to the fact that the methods show high control properties, the best one should be chosen after considering minor differences between them. Thus, the PCi-3L method shows the lowest grid current THD for all the tested conditions, but it requires the greatest number of calculations. The DPC-3L-3A method requires less calculation time; however, it operates with a bit higher THD values. The DPC-3V-3L method is characterized by the highest THD current of all three methods (but still lower than for the VOC). However, in contrast to both nonlinear methods described, the DPC-3V-3L uses an SVM modulator that ensures constant switching frequency as well as lower sampling period.

Acknowledgements. The work was supported by research project S/WE/3/2013 funded by the Polish Ministry of Science and Higher Education.

\section{REFERENCES}

[1] Y. Suh, Y. Go, and D. Rho, "A comparative study on control algorithm for active front-end rectifier of large motor drives under unbalanced input", IEEE Transactions on Industry Applications, 47 (3), 1419-1431 (2011).

[2] A. Sikorski and M. Korzeniewski, "Comparison of properties of the three-level DC/AC inverter controlled by DTC-ST and DTC-SVM methods", Przeglad Elektrotechniczny 84 (6), $117-120$ (2008)

[3] R. Wandhare and V. Agarwal, "Novel integration of a PV-wind energy system with enhanced efficiency", IEEE Trans. Power Electron. 30 (7), 3638-3649 (2015).

[4] K. Ma and F. Blaabjerg, "Modulation methods for neutral-pointclamped wind power converter achieving loss and thermal redistribution under low-voltage ride-through", IEEE Trans. Ind. Electron. 61 (2), 835-845 (2014).

[5] S. Kouro, M. Malinowski, K. Gopakumar, J. Pou, L. Franquelo, B. Wu, J. Rodriguez, M. Perez, and J. Leon, "Recent advances and industrial applications of multilevel converters", IEEE Trans. Ind. Electron. 57 (8), 2553-2580 (2010).

[6] H. Abu-Rub, S. Bayhan, S. Moinoddin, M. Malinowski, and J. Guzinski, "Medium-voltage drives: Challenges and existing technology", in IEEE Power Electronics Magazine 3 (2), 29-41 (2016).

[7] P. Wiatr and M.P. Kazmierkowski, "Model predictive control of multilevel cascaded converter with boosting capability - a simulation study", Bull. Pol. Ac.: Tech 64 (3), 581-590 (2016).
[8] A. Godlewska, R. Grodzki, P. Falkowski, M. Korzeniewski, K. Kulikowski, and A. Sikorski, "Advanced control methods of DC/AC and AC/DC power converters - look-up table and predictive algorithms", Advanced Control of Electrical Drives and Power Electronic Converters, ed. Jacek Kabziński, Springer International Publishing, Cham, 221-302, 2017.

[9] I. Lopez, S. Ceballos, J. Pou, J. Zaragoza, J. Andreu, I. Kortabarria, and V. Agelidis, "Modulation strategy for multiphase neutralpoint clamped converters", IEEE Trans. Power Electron., 31 (2), 928-941 (2016).

[10] J. Rodriguez, S. Bernet, P.K. Steimer, and I. E. Lizama, "A survey on neutral-point-clamped inverters", IEEE Transactions on Industrial Electronics 57 (7), 2219-2230 (2010).

[11] J.R. Rodriguez, J. W. Dixon, J.R. Espinoza, J. Pontt, and P. Lezana, "PWM regenerative rectifiers: state of the art", IEEE Transactions on Industrial Electronics 52 (1), 5-22 (2005).

[12] M. Malinowski, M.P. Kaźmierkowski, and M. Jasiński, "Simple direct power control of three-phase PWM rectifier using space vector modulation (DPC-SVM)", IEEE Trans. Ind. Electron 51 (2), 447-454 (2004).

[13] K. Kulikowski and A. Sikorski, "New DPC look-up table methods for three-level AC/DC converter", IEEE Transactions on Industrial Electronics 63 (12), 7930-7938 (2016).

[14] J. Scoltock, T. Geyer, and U.K. Madawala, "Model predictive direct power control for grid-connected NPC converters", IEEE Transactions on Industrial Electronics 62 (9), 5319-5328 (2015).

[15] A. Sikorski and R. Grodzki, "Predictive control of the AC/DC converter", 16th International Power Electronics and Motion Control Conference and Exposition, Antalya, 131-136 (2014).

[16] X. Wang, F. Blaabjerg, and P.C. Loh, "Virtual RC damping of LCL-filtered voltage source converters with extended selective harmonic compensation", IEEE Transactions on Power Electronics 30 (9), 4726-4737 (2015).

[17] S. Piasecki, M. Jasinski, K. Rafal, M. Korzeniewski, and A. Milicua, "Higher harmonics compensation in grid-connected PWM converters for renewable energy interface and active filtering", Przeglad Elektrotechniczny 87 (6), 85-90 (2011).

[18] L. Hadjidemetriou, E. Kyriakides, and F. Blaabjerg, "A robust synchronization to enhance the power quality of renewable energy systems", IEEE Transactions on Industrial Electronics, 62 (8), 4858-4868 (2015).

[19] M.P. Kazmierkowski, M. Jasinski, and G. Wrona, "DSP-based control of grid-connected power converters operating under grid distortions", IEEE Transactions on Industrial Informatics, 7 (2), 204-211 (2011).

[20] J.A. Rohten et al., "Model predictive control for power converters in a distorted three-phase power supply", IEEE Transactions on Industrial Electronics 63 (9), 5838-5848 (2016).

[21] Y. Zhang, C. Qu, and J. Gao, "Performance Improvement of direct power control of PWM rectifier under unbalanced network", IEEE Transactions on Power Electronics 32 (3), 2319-2328 (2017).

[22] J. Rodriguez and P. Cortez, Predictive Control of Power Converters and Electrical Drives, J. Wiley \& Sons, Chichester, 2012.

[23] M.P. Kazmierkowski, R. Krishnan, and F. Blaabjerg, Control in Power Electronics, Academic Press, USA, 2002.

[24] P. Antoniewicz, "Predictive control of three-phase ac/dc converters", PhD Thesis, Warsaw University of Technology, 2009. 